Disclosure of Interest None Declared.

\section{PWE-045 HAS COLONOSCOPY BECOME A TEST TO FIND INCIDENTALOMAS?}

J George*, K Manoj. Gastroenterology, Wrexham Maelor Hospital, Wrexham, UK

\subsection{6/gutjnl-2014-307263.305}

Introduction Demand for colonoscopy has risen over the years and many hospital trusts in the UK are struggling to cope with the demand. This causes many deserving patients waiting longer for the procedure resulting in increasing patient anxiety along with potential clinical risks of delayed diagnosis. We were interested in looking at the correlation between indications and findings at colonoscopy and to explore the possibility of refining the referral criteria to improve diagnostic yield and to reduce demand. We had a specific interest in rectal bleeding as a symptom.

Methods Colonoscopy data for 2013 was sought giving us a total of 2021 porcedures which was retrospectively analysed by using the reporting software. This number was then filtered by indications for colonoscopy which included rectal bleeding with or without associated factors which left 378 . We analysed all the pathology in particular that which was proximal to the splenic flexure and whether the findings showed a causal link to the indication.

Results There were $52(13.8 \%)$ procedures among these which found pathology proximal to splenic flexure and therefore beyond the extent of examination of flexible sigmoidoscopy that can directly be linked to the symptoms. Of these 52, 12 (3.2\%) were attributed to the indication for the referral. $86.2 \%$ of

\section{Pie chart representingall colonoscopies performed in 2013 with rectal bleeding as part of the indication}
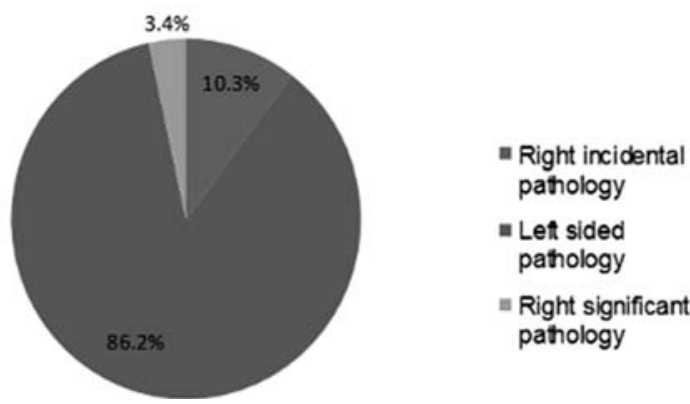

Abstract PWE-045 Figure 1 colonic pathology could be found potentially using flexible sigmoidoscopy. Looking at the indications in detail in relation to significant pathology proximal to the splenic flexure only; diarrhoea (8/69) $11.6 \%$, iron deficiency anaemia (1/30) 3.3\% and bleeding only (2/89) $2.2 \%$ had significance.

Conclusion Colonic pathology proximal to splenic flexure with a causal link to the indication is rare when investigating rectal bleeding unless associated with diarrhoea. Flexible sigmoidoscopy may be more appropriate in other instances.

Disclosure of Interest None Declared.

\section{PWE-046 EYE TRACKING ASSESSMENT SUGGESTS FASTER TIME TO DETECTION AND GREATER ATTENTION SPAN FOR DYSPLASTIC LESIONS WITH AUTOFLUORESENCE COMPARED TO WHITE LIGHT ENDOSCOPY}

J Ariyaratnam*, N Mohammed, V Subramanian. Department of Gastroenterology, Leeds Teaching Hospitals, Leeds, UK

\subsection{6/gutjnl-2014-307263.306}

Introduction Surveillance endoscopy is crucial to the management of Barrett's oesophagus to diagnose and treat dysplasia. Recent studies have confirmed that increased time of inspection of the Barrett's mucosa increases detection rates. However increasing inspection time has both clinical and economic implications. Advanced imaging techniques like autofluoresence imaging (AFI) improves detection of dysplastic lesions, but little on known about the time taken to detect abnormalities with these modalities.

Methods We presented a series of endoscopic images of dysplastic lesions within the oesophagus to novice endoscopists on a computer screen. Each of the 10 lesions was presented in white light endoscopy (WLE) and AFI modes. The subjects reviewed these images in a random order with 10 seconds for each image. They were tasked with identifying the lesion as fast as possible and fixating on it for the duration of presentation. An eye tracking system (Grinbath eye tracker, College Station Texas) was used to record eye movements of the subjects and we calculated the amount of time it took to fixate on the lesion and the percentage attention time on each lesion.

Results A total of 26 novice endoscopists were recruited to the study, resulting in a total of 260 presentations of WLE images and 260 presentations of AFI images. The average time to fixation on the lesion was significantly less $(p<0.05)$ in AFI $(5.47$ seconds) compared to WLE (6.17). In addition, the percentage attention span on the lesion following detection was significantly greater for AFI $(58.12 \%)$ than WLE $(49.96)(\mathrm{p}<0.0005)$.

Abstract PWE-045 Table 1 Table to show the indications with rectal bleeding in relation to right side and left sided colonic pathology

\begin{tabular}{|c|c|c|c|c|c|}
\hline $\begin{array}{l}\text { Indication } \\
\text { (Bleeding +) } \\
\end{array}$ & $\begin{array}{l}\text { Right sided } \\
\text { colonic pathology }\end{array}$ & $\begin{array}{l}\text { Left sided } \\
\text { colonic pathology }\end{array}$ & $\begin{array}{l}\text { Ride sided cause } \\
\text { for the indication }\end{array}$ & $\begin{array}{l}\text { Total number of } \\
\text { colonoscopies }\end{array}$ & $\begin{array}{l}\text { Percentage of } \\
\text { right sided causes } \\
\text { for the indication }\end{array}$ \\
\hline Abnormal sigmoidoscopy or CT Scan & 5 & 23 & 0 & 28 & $0.0 \%$ \\
\hline Positive family history, previous polyps or national screening & 10 & 31 & 0 & 41 & $0.0 \%$ \\
\hline Previous carcinoma & 1 & 3 & 0 & 4 & $0.0 \%$ \\
\hline Constipation & 1 & 14 & 0 & 15 & $0.0 \%$ \\
\hline Constipation and ciarrhoea & 0 & 23 & 0 & 23 & $0.0 \%$ \\
\hline Bleeding only & 11 & 77 & 2 & 89 & $2.2 \%$ \\
\hline Diarrhoea & 10 & 59 & 8 & 69 & $11.6 \%$ \\
\hline Iron deficiency anaemia & 5 & 25 & 1 & 30 & $3.3 \%$ \\
\hline
\end{tabular}


Conclusion AFI reduces time to detection in novice endoscopists and could be a valuable training tool for trainees to improve their skills in detecting dysplasa in a time efficient manner. Advanced imaging endoscopic techniques may therefore help trainee endoscopists more than experienced endoscopists. Disclosure of Interest None Declared.

\section{PWE-047 WHEN SHOULD I TAKE TERMINAL ILEAL BIOPSIES? EXPERIENCE FROM A SINGLE UNIT}

${ }^{1,2} \amalg$ Neilson*, ${ }^{1,2} \mathrm{R}$ Bevan, ${ }^{1,2,3} \mathrm{CJ}$ Rees. 'South Tyneside District Hospital, South Shields, UK; ${ }^{2}$ Northern Region Endoscopy Group, Newcastle, UK; ${ }^{3}$ School of Medicine, Pharmacy and Health, Durham University, Stockton-on-Tees, UK

\subsection{6/gutjnl-2014-307263.307}

Introduction Terminal ileum (TI) intubation at colonoscopy may be useful in the investigation of patients with diarrhoea or possible inflammatory bowel disease (IBD). ${ }^{1,2}$ The yield of TI biopsies is variable and there are no standards for current practice. ${ }^{2,3}$ Furthermore, in the UK concerns remain regarding the potential for prion transmission.

Methods We aim to establish the yield of TI biopsies in a single unit. All TI biopsies recorded on the pathology system in a 3year period were reviewed. Colonoscopy reports and case notes were reviewed to establish if biopsy results were clinically relevant (defined as altering management). Statistical analysis was performed using SPSS. P values were calculated using Fisher's exact test to show any difference in biopsy yield between normal and abnormal looking mucosa for each indication. The values were calculated for all abnormal biopsy results and clinically relevant biopsy results.

Results 129 TI biopsies were taken between September 2010 and September 2013, 49 (38\%) male and 80 (62\%) female. Mean age 44 years (s.d. 17.2). There were 29 (22.5\%) cases of known IBD. 5 (3.9\%) cases were completion colonoscopies after colorectal cancer surgery where TI biopsies are taken to prove a complete examination.

Conclusion We demonstrate that when investigating patients with diarrhoea, abdominal pain or IBD, if the terminal ileum is visually normal, biopsies do not add to the clinical picture. There is a higher yield of relevant biopsy abnormalities when the TI appears abnormal. We can recommend within our practice that visual assessment of a normal terminal ileum is adequate, thereby reducing unnecessary biopsies. This reduces the workload for pathology laboratories, reduces risk from biopsies and improves patient care as normal results can be communicated sooner to the patient.

\section{REFERENCES}

1 Morini $S$, et al. Retrograde ileoscopy in chronic nonbloody diarrhea: a porspective, case-control study. Am J Gastroenterol 2003;98(7):1512-15

2 Geboes K, et al. Is ileoscopy with biopsy worthwhile in patients presenting with symptoms of inflammatory bowel disease? Am J Gastroenterol 1998;93(2):201206

3 Melton SD, et al. lleal biopsy:Clinical indications, endoscopic and histopathologic findings in 10,000 patients. Dig Liver Dis 2011;43(3):199-203

Disclosure of Interest None Declared.

\section{PWE-048 RECURRENCE RATES FOLLOWING PIECEMEAL RESECTION OF 2 CM ADENOMATOUS POLYPS}

${ }^{1} \mathrm{M}$ Harling ${ }^{*},{ }^{1} \mathrm{~K}$ Kandiah, ${ }^{2} \mathrm{Z}$ Tsiamoulos, ${ }^{1} \mathrm{G}$ Smith, ${ }^{2} \mathrm{~B}$ Saunders, IJ Martin. ${ }^{1}$ Gastroenterology Department, Imperial College Healthcare NHS Trust, London, UK; ${ }^{2}$ Wolfson Unit for Endoscopy, St Mark's Hospital, London, UK

\subsection{6/gutjnl-2014-307263.308}

Introduction Piecemeal endoscopic mucosal resection (pEMR) is a minimally invasive endoscopic technique for the resection of sessile/flat colorectal polyps (larger than $2 \mathrm{~cm}$ ). It has been suggested that patients should have a check procedure at 3 or 6 months to ensure complete initial excision of the lesion, and subsequent colonoscopic surveillance at between 1 and 3 years to identify recurrence.

Methods This is a retrospective observational audit, including all patients with sessile/flat colorectal polyps of more than $20 \mathrm{~mm}$ in diameter who underwent pEMR in 2010, across 4 London Teaching Hospitals. Patients were either local or tertiary referrals. Data was obtained from colonoscopy and histology reports. The primary outcome measured was the follow up rate at first, check colonoscopy ( 3 months, 6 months or 1 year), and at the subsequent surveillance colonoscopy (1, 2 or 3 years). Recurrence rate at both check and surveillance was a secondary outcome. A high-risk recurrence was considered to be more than or equal to $10 \mathrm{~mm}$ and a low-risk recurrence less than $10 \mathrm{~mm}$.

Results 153 patients were included in the cohort; 53 (34.6\%) patients were local referrals and $100(65.4 \%)$ were tertiary referrals. $128(83.6 \%)$ patients had a check colonoscopy and 74 patients $(49.0 \%)$ had a surveillance colonoscopy. Adenoma recurrence occurred in 44 (34.4\%) patients at check colonoscopy, with $3(2.4 \%)$ polyps having high-risk recurrence, and in 12 (16.3\%) patients at surveillance colonoscopy, with 3 (4.1\%)

\begin{tabular}{|c|c|c|c|c|c|c|c|}
\hline \multirow[t]{2}{*}{ Indication (n) } & \multicolumn{3}{|c|}{ Ileoscopy abnormal } & \multicolumn{3}{|c|}{ lleoscopy normal } & \multirow[t]{2}{*}{ P value (all/ clinically relevant) } \\
\hline & Number & Biopsy abnormal & Clinically relevant & Number & Biopsy abnormal & Clinically relevant & \\
\hline $\begin{array}{l}\text { Diarrhoea } \\
(67)\end{array}$ & 15 & 11 & 9 & 52 & 7 & 3 & $<0.001 /<0.001$ \\
\hline $\begin{array}{l}\text { Abdo pain } \\
\text { (39) }\end{array}$ & 12 & 9 & 8 & 27 & 3 & 2 & $<0.001 /<0.001$ \\
\hline $\begin{array}{l}\text { IBD assessment } \\
\text { (29) }\end{array}$ & 12 & 10 & 9 & 17 & 3 & 3 & $<0.001 / 0.006$ \\
\hline $\begin{array}{l}\text { Other* } \\
\text { (18) }\end{array}$ & 2 & 2 & 1 & 16 & 3 & 1 & $0.194 / 0.284$ \\
\hline $\begin{array}{l}\text { Total } \neq \\
(129)\end{array}$ & 34 & 25 & 21 & 95 & 14 & 1 & $<0.001 /<0.001$ \\
\hline
\end{tabular}

